\title{
The use of recreational urban parks in Johannesburg: a phenomenological study of place attachment in Thokoza Park in Moroka, Soweto
}

\author{
H. Radebe ${ }^{1} \&$ D. Irurah ${ }^{2}$ \\ ${ }^{1}$ School of Animal, Plant and Environmental Science, \\ University of the Witwatersrand, South Africa \\ ${ }^{2}$ School of Architecture and Planning, \\ University of the Witwatersrand, South Africa
}

\begin{abstract}
Over the years, urban recreational parks have experienced a decline in the proportion of users even though urbanization has been on the rise. Some researchers have attributed this to some residents reporting that they feel exposed and vulnerable to crime and human scrutiny hence their reduced use of these spaces. This study applies place attachment framework to Thokoza Park in Johannesburg, South Africa, as a case study towards understanding the park's uniquely high level of user-attraction and also identifies key lessons for other similar parks in Johannesburg in general.

Phenomenological research design was used where direct observation of Thokoza Park users was complemented by interviews of the park's users as data collection tools. A spread-sheet tool was used to organize and process the data.

The study found that a high-level of place attachment plays an important role towards the use of Thokoza Park. In assessing place identity and place dependency, the study found that park users need to be emotionally attached to the park, be able to identify with it and be dependent on the park to meet their outdoor recreational needs. The results of the study demonstrated how the level of place attachment is influenced by key factors such as diversity and quality park amenities, trust among users and surrounding communities, level of safety, accessibility, design and the maintenance of the park. The findings also highlight
\end{abstract}


the importance of understanding the social dynamics within adjoining communities as this would also influence the level of use of such parks.

Keywords: urban recreational parks, phenomenology, users, place dependency, place identity, place attachment, passive recreational activities, active recreational activities, amenities, observations, park design.

\section{Introduction}

\subsection{Background}

Urban recreational parks form part of the open space system that are freely provided by the local government in support of well-being and quality of life for urban residents (Sanesi and Chiarello [1]). Urban recreational park is land that has been earmarked for public use to facilitate outdoor recreational activities and form part of open spaces (Henderson [2]; Solecki and Welch [3]). The activities can be passive or active thus catering to a broad range of user groups and interests. Urban recreational parks provide its users with multiple benefits which fall into socioeconomic, environmental and psychological categories (Solecki and Welch [3]). The size of an urban recreational park varies depending on the purpose of the park and such parks can be distinguished by the features/amenities (natural and manmade) they provide to the users. They constitute an integral part of modern urban active and passive recreation. Although urban recreational parks have always been a part of cities they now compete with other places of leisure such as malls and sports/playgrounds. The factors which influence the level of such spaces include demographic, economic, and social characteristics of users as well as environmental and physical infrastructure of the park, including its management/maintenance regime.

Literature on the benefits of open spaces for urban residents is immense and increasing. Such studies show that open spaces are an important part of the city as they offer social-cultural, economic and environmental benefits to people and cities (Haq [4]; and later Konijnendijk et al. [5]). The benefits include outdoor recreational services, clean air, enhancement of city image, improved mental and physical health, reduced noise levels, increased property value and moderation of urban microclimates (Chiesura [6]; and Sutton [7]). The importance of such places has been recognized and forms part of the proposed United Nations Sustainable Development Goals (SDGs) (ICSU \& ISSC [8]).

According to De Ridder et al. [9], the valuing of urban green environments has increased in the past years, especially given the increased recognition of the benefits (utility) of such environments to the residents. Increased attention has been invested in available open spaces in cities as they play an important role in improving people's quality of life thus making cities livable and sustainable (Chiesura [6]; Sutton [7] and Konijnendijk et al. [5]). In their analyses of the origins of open spaces, Hayward and Weitzer [10]) stated that open spaces were originally created to provide tranquility and outdoor leisure environments for urban residents. Godbey [11] adds that designers of outdoor spaces were concerned about people's increased indoor lifestyle that minimised physical 
activity and undermined well-being. Urban parks were thus created to encourage urban residents to spend more time outdoors and thus encourage active lifestyles.

Hayward and Weitzer [10] and Chiesura [6], further mention that over the years open spaces have attracted a declining proportion of users even as urbanization intensifies. This decreased association with open spaces has been attributed to an increase in negative perceptions of such spaces which leads to emotional disconnect and detachment. Furthermore, studies have shown that some residents feel exposed and vulnerable to crime and human scrutiny in urban parks (Hayward and Weitzer [10] and Chiesura [6]. Additionally, people are changing their recreational needs and habits such that in most instances open spaces no longer cater to contemporary recreational needs (Hayward and Weitzer [10]). Instead, those who can afford membership have shifted to indoor sports or activities such as membership-based gyms rather than open public parks.

\subsection{Urban park design}

The benefits that urban residents gain from utilizing urban park facilities are highly dependent on the design of the park. According to Kemperman and Timmermans [12], urban park design should consider physical and emotional accessibility as one of the critical characteristics. Physical access includes users being able to reach the park either on foot, by private cars, buses and taxis. Barriers such as fencing around the park, unattractive facilities or the feeling of being insecure can compromise accessibility. Rabare et al. [13] argues that the design, location and amenities play an essential role in attracting urban park users. Furthermore his study emphasizes that urban parks must be appealing and must engender enjoyable experience and sustain positive emotions. The facilities must respond to the complexities of social, cultural and physical needs of people from different cultures, age and gender. Although planners and designers of urban parks are knowledgeable about design and the importance of such spaces, they are not always certain of people's needs especially where such needs keep shifting. Residents should therefore be consulted during the design process of such urban parks. According to CABE SPACE [14] such consultation enhances residents' sense of ownership of the spaces as they are more likely to reflect user identity and culture values thus enhancing the potential of utilization. However, this should not compromise on the overall principles of good park design and subsequent management.

\subsection{Place attachment}

The concept of place attachment introduces the emotional relationship that people develop in the process of their interaction with their physical landscapes and geographical areas. The relationship is often positive and often results in people feeling safe thus affording them a sense of identity and belonging. Morgan [15] notes that people develop strong associations with geographic areas over a long time through their intentional interactions with the related landscapes. The study further argues that a stronger relationship between people and a geographic area develops if people have interacted with a place over a long time of their history. 
Livingston et al. [16] further expands on the notion that strong place attachment develops when a given geographical area satisfies the needs of the people and offers a unique experience which the people can identify with. A strong place attachment indicates that the individual has found meaning in and through the place. This can develop at an individual level or group level. At the individual level, personal connections are formed with the place and this promotes selfidentity, while at group levels such places enhance shared values, cultures and religion thus promoting a sense of commonality and community (Livingston et al. [16]). The concept of place attachment is relevant to this study as it was hypothesized to play an important role in influencing the level of use of urban recreational parks. Urban park users with strong place attachment tend to invest a lot of their time and emotions (mainly positive) at the park.

Place attachment is often analysed under two dimensions which are place identity and place dependence. Place identity represents people's emotional bond with place while place dependence reflects a practical bond (utilitarian/usage dimension). Place attachment develops over time and contributes to a strong sense of place and self-identity that is built up through life experiences in the course of interaction with the place (Livingston et al. [16] and Budruk et al. [17]). Ramkissoon et al. [18] explains that when an individual develops a practical bond with a place, the individual becomes loyal to the place and is therefore more likely to be committed to the well-being of the place in return. This would be in contrast to experiences of indifference which would contribute to detachment and possibly to the neglect of place.

The following research questions were applied to guide the study:

1. What is Thokoza Park's physical attributes and the phenomenological experiences it engenders for its users?

2. How is Thokoza Park used by residents of Soweto and the city of Johannesburg in general?

3. What levels of place dependency and place identity characterize the interaction between the users and Thokoza Park as a public recreational park?

4. How does use-intensity interact with place attachment among Thokoza Park users?

5. What key principles can be extracted for application to similar parks in Johannesburg?

In answering the research questions, this study contributes towards assisting urban planners on improving urban parks to meet people's outdoor recreation demands and desires as a key component of a sustainable city outcomes/goals for Johannesburg. The study also evolves key principles on how to improve userattraction in other urban parks so as to attract new urban park users in other parks where usage is weak. This is inspired by the well-understood co-relation between outdoor recreational activities with health and well-being as well as overall quality of life of urban residents as opposed to passive indoor leisure, work or play. 


\section{Methodology}

The study was conducted at Thokoza Park which is situated in Moroka, Soweto and located 35 kilometers south west of Johannesburg. The park covers 4.5 hectares of land and it is both a flagship and a regional park because of its considerable size and the large number of people it attracts - people in close proximity and those living outside Soweto.

The study applied a qualitative case study research approach which allowed the researcher to explore the relationship between user interactions with the park as their environment. Within a specific case study scenario, the relationship focused on residents of Moroka and Thokoza Park in Soweto. This allowed for an understanding of why the park (Thokoza Park) is highly utilized compared to other urban parks in Johannesburg. Based on appraisal guided by place dependence and place identity, the study was based on a combination of primary and secondary data. Primary data needed for the study were collected with a variety of data collection tools which included maps, direct observations (notes and sketches), photographs and face to face interviews. Observations were conducted in summer month three times during weekdays and once during the weekend. The observation data were collected over one hour intervals in the morning (9:00 to 10:00), early afternoon (12:00 to 13:00) and late afternoon (15:30 to 16:30). It was important to observe the activities at the park at different times of the day and different days of the week as time is one of the key factors influencing park use. Each session of observation involved counting the number of users at the park and then followed by observing user-behavior patterns. The extent to which these activities were influenced by time, weather, social factors and general functionality of the park was also noted.

The study interviewed 20 park users selected on the basis of user-type and willingness to participate in the study. The sample of respondents was therefore not intended to be a random sample and therefore no statistically motivated inferences have been used in the analysis and findings of the study. The survey was divided into five sections. Section one addressed the demographic information of the participants (gender, age, level of education, employment status and where the participants live). The second section addressed participant's needs for using Thokoza Park. Under section three users were further asked about their perceptions of the urban park design. Section four and five addressed the participant's place dependence and place identity in relation to Thokoza Park, respectively. Section three to five were structured in line with a five point Likert scale with (1) representing strongly disagree to (5) being strongly agree. The Likert scale was developed to measure attitudinal responses. Secondary data helped with the understanding of the theoretical background involved in the topic as well as allowing access to other case studies reported in the literature. Both secondary and primary data were analysed based on an integrative approach towards answering the key research questions of the study. 


\section{Results}

On primary data, 28 users were approached for face to face interviews but only 20 users consented to participate in the study. Of the 20 participants $40 \%$ were female users. This number is supported by the data from direct observations, whereby per day, majority of the park users at any given time during both weekends and weekdays were males. From the questionnaire $20 \%$ of the respondents were between the ages of 18 to 21 years while $45 \%$ were between the ages of 22 to 30 years. Only $25 \%$ and $10 \%$ of the participants were between the ages of $31-40$ and 41-50 years respectively.

\subsection{Park utilization}

Participants indicated that they visit the park mostly once a week with only $5 \%$ indicating that they visit more than three times a week. Almost $25 \%$ of the respondents indicated that they come to the park occasionally i.e. either once every four months, when invited or during holidays. The visits under which the participants indicated $100 \%$ were during the weekends with only $10 \%$ also indicating that they visit during week days. During weekdays park activity increased late afternoon compared to mornings. The majority $(65 \%)$ of the park visits lasted between 4-6 hours, $15 \%$ stayed for more than 6 hours per visit at the park. This is also supported by direct observations, as most Thokoza Park users were observed to spend more than two hours at the park. On the access factor, $40 \%$ of participants indicated that they spend 11-20 minutes to reach the park from home, while $30 \%$ spent less than 10 minutes and $20 \%$ spent $21-30$ minutes to get to the park.

The most frequently used mode of transport by park users from home was by foot/walking (60\%). Other transport modes included buses, cars and mini-bus taxis (the commonly used mode of public transport in South African cities). Ninety percent $(90 \%)$ of the participants indicated that they spent their time at the park with their family and friends and $10 \%$ with partners. During the weekdays and before 12:00pm, most Thokoza Park users were visiting the park by themselves with very few people in pairs or groups. However, this changed in the afternoon when the park was mostly occupied by young/school learners in groups. On the factor of duration of use, $50 \%$ of the participants indicated that they have been using the park for less than 5 years while the other $50 \%$ have been using the park for more than 6 years.

\subsection{Factors influencing the use of Thokoza Park}

Thokoza Park participants indicated that they engage in a number of activities at the park. In order to understand why/how respondents use the park, participants were asked "Why do you come to Thokoza Park?". The results indicate that most respondents visit the park to meet with friends and spend time with family. Furthermore, study participants indicated that they were drawn to the park as it provided them with an area to be able 'to relax' and to get 'fresh air'. This indicates the role urban parks play in strengthening family and social ties, urban 
parks provide city residents with outdoor areas that allow for personal space to relax and to spend time alone, with family or a partner (Loures and Costa [19]). Chiesura [6] argued that apart from spending time with familiar faces, parks allow for urban park users to engage with other users. This helps to build community bonds as parks create opportunities for park users to have dialogues with each other and also creates new or enhances existing social networks.

Most of the activities respondents engaged in were passive activities such as to meet friends and family, relax, for fresh air and also picnics. Other activities included sport, spending time with children, escaping from the city, listen to and observe nature and to get inspiration. Similar activities were also observed during weekdays and weekends but there was more variety in user-activities over weekends compared to weekdays (solitary activities, social activities, food related activities, team activities, physical and community activities).

When participants were asked about the most prevalent feelings they experience while at the park the majority of the participants reported that they experience a sense of relaxation and happiness while at the park. The participants reported that the feelings have important influence on their daily wellbeing and were therefore a key contributing factor to their frequent visits to the park. These findings indicate urban parks have psychological health and general well-being benefits.

The design and facilities were also essential in attracting users to Thokoza Park. Using the Likert scale participants were asked to rank the design of Thokoza Park using three statements; (1) Thokoza Park is well organized, (2) Thokoza Park has a convenient layout and (3) Thokoza Park is well designed. More than 50\% of the participants agreed that Thokoza Park was well organized as a park while a few could neither agree nor disagree. Furthermore the majority of the participants agreed that Thokoza Park has a convenient layout and is well designed.

\subsection{Place attachment}

Place dependence and place identity were measured based on responses to ten statements. To examine place dependence participants were asked to respond to four statements: (1) Thokoza Park provides me with what I need, (2) Thokoza Park is the best place for me to fulfill my need(s), (3) I am committed to Thokoza Park because it gives me what I need and, (4) Thokoza Park is the best alternative for my goals and needs. Majority of the participants agreed on the statements indicating the degree to which they feel Thokoza Park facilitates their recreational needs and goals. None of the participants strongly disagreed with the statements but a number of participants could neither agree nor disagree with the statements. This was particularly so with regard to the statement about Thokoza Park being the best alternative for their goals and needs.

There was a high level of agreement with statements that were used to measure the degree to which Thokoza Park users are emotionally attached to the park. Over 15 participants agreed with the following statements: I feel happy when I am at Thokoza Park and I feel excited when I am at Thokoza Park. More than 50\% participants disagreed with the statement that they feel scared while at Thokoza Park. However, it is important to indicate that a small number of participants 
reported that they feel scared while at the park. According Erkip [20] people's perceptions play a significant role in the utilization of urban parks and when urban park users feel insecure or sense that their personal space is threatened they are likely to develop negative feelings towards a park and its facilities. This is likely to discourage them from accessing and using the park with the added risk of such feelings becoming a hidden/subconscious barrier among potential park users.

There was a high level of agreement with the statements provided to the participants to measure place identity at Thokoza Park. Fifteen participants agreed that they identify with Thokoza Park while only half of the participants agreed that Thokoza Park reflects who they are. Ten statements were used towards assessing the level of place attachment. These incorporated place dependence, emotional attachment and place identity. On average participants at Thokoza Park had higher level of emotional attachment to Thokoza Park followed by place identity. Place dependence had the lowest average. Between males and females, males showed a slightly stronger place attachment compared to females, particularly with place dependence that has higher averages for males compared to females. However, results also indicate that more females than males felt vulnerable and unsafe at Thokoza Park given that more females said they felt scared while at Thokoza Park.

\section{Discussion and conclusion}

In alignment with other similar studies internationally, this study finds that place attachment plays an important role towards the use of Thokoza Park. In assessing place identity and place dependency, the study found that park users need to be emotionally attached to the park, be able to identify with it and feel dependent on the park for their outdoor recreational needs. The study further found that the level of place attachment is influenced by the facilities that are provided at the park, trust among community members as well as the design and the maintenance of the park. Although the park is located in an area experiencing prevailing levels of criminal activity for Johannesburg in general, this does not seem to be inhibiting users from using the park compared to low use of other similar parks located in relatively safer neighbourhoods such as the middle and upper-class suburbs of the city. Thus, even though safety, design, maintenance and accessibility are critical for high level use of urban parks, the study seems to suggest that they can only be viewed as complementary to level of trust among community members which most likely serves as the primary factor. Furthermore, there seems to be a unique need for outdoor recreation spaces such as urban parks in Soweto neighbourhoods such as Moroka where households have small private yards and therefore residents are therefore prone to be attracted to socialize in public spaces such as parks. The ability of the users to meet their recreation needs at the park encourages a diverse range of users to continue using the park as this contributes to an enjoyable experience individually and in groups thus reinforcing positive emotions towards the park. It can be argued that the users' well-being also improved as they further utilized the park.

This emphasizes the significance of place attachment towards gaining the benefits provided by place (in this instance, an urban recreational park), within a 
context of a broader neighborhood and community dynamics. Urban recreational parks have a broad range of both direct and indirect benefits for the users. However, in order to fully reap the benefits, a strong sense of place attachment needs to be nurtured particularly if park users want psychological and spiritual benefits arising from interacting with nature (Louv [21]). Chiesura [6] highlights that this contributes to the experienced quality of life of the users and further plays a critical role in making cities more sustainable.

It can therefore be acknowledged that there is a positive relationship between level-of-use and level of place attachment to urban parks. A strong level of use increases the level of place attachment and in return a strong level of place attachment enhances park utilization. It can therefore be concluded that investment in urban recreational parks by park managers and policy makers should focus on increasing both the level-of-use and level of place attachment in order to ensure continuous utilization of urban parks as well as to attract new users to the parks. Furthermore, park managers and policy makers need to take into account social dynamics such as the awareness of benefits-of-use of urban recreational parks among urban residents in general as well as levels of trust within host-communities as complementary interventions/factors to the design/facilities of urban parks in order to ensure that the parks are adequately utilised.

In conclusion the study finds that the, appropriate design and systematic maintenance regime of Thokoza Park promotes physical well-being, socializing, and social networks of the neighboring communities. As a result, the findings support the broader expectation that the way the park is designed, the type of amenities it has and its maintenance regime influences potential positive or negative experiences by park users which would in turn influence their overall place attachment. Despite the common challenges that threaten their use, urban recreational parks are an important asset for urban communities. The utilization of the park facilities provides many benefits that urban residents require and should therefore not be traded-off against other places of leisure or amenities such as malls or gyms. However, for urban recreational parks to continue being utilized and to attract more people, planners and designers will need to regularly reflect and appraise human needs and their lifestyles in order to continue being responsive and adaptable to the changing needs of urban residents in relation to outdoor recreational opportunities.

Future research addressing factors that contribute to increased use of urban recreational parks should investigate not only factors within the park boundaries but also include external factors such as the socio-economic factors in the neighboring/host community as these may impact on the use or disuse of urban recreational parks. Furthermore it would be ideal to include a study on a counter case where the level of use is weak in spite of good quality facilities/design and management of the park in order to understand extent to which subconscious barriers/perceptions could be inhibiting users from accessing and using such a park. Such examples are known to exist in Johannesburg, and especially in its middle and upper-income neighbourhoods. This would improve our overall understanding of why similar urban recreational parks (size, design and amenities), but in different neighborhoods, experience different levels of use such 
that one park becomes more utilized than another, even when the underlying need for outdoor recreation is still discernable.

\section{References}

[1] Sanesi, G. \& Chiarello, F., Residents and urban green spaces: The case of Bari. Urban Forestry and Urban Greening, 4, pp. 125-134, 2006.

[2] Henderson, J.C., Urban parks and green spaces in Singapore. Managing Leisure, 18(3): 213-225, 2013.

[3] Solecki, W.D. \& Welch, J.M. Urban parks: green spaces or green walls? Landscape and Urban Planning, 32, pp. 93-106, 1995.

[4] Haq, S.M.A., Urban green spaces and an integrative approach to sustainable environment. Journal of Environmental Protection, 2, pp. 601-608, 2011.

[5] Konijnendijk, C.C., Annerstedt, M., Nielsen, A.B. \& Maruthaveeran, S, Benefits of urban parks: A systematic review. Report FOR-IFPRA, International Federation of Parks and Recreation Administration, 2013.

[6] Chiesura, A., The role of urban parks for the sustainable city. Landscape and Urban Planning, 68, pp. 129-138, 2004.

[7] Sutton, C.M., Urban open space: A case study of Msunduzi Municipality, South Africa. MSc thesis. Queen's University, Ontario, Canada, 2008.

[8] ICSU \& ISSC, Review of the Sustainable Development Goals: The Science Perspective. Paris: International Council for Science (ICSU), 2015.

[9] De Ridder, K., Adamec, V., Bañuelos, A., Bruse, M., Bürger, M., Damsgaard, O., Dufek, J., Hirsch, J., Lefebre, F., Pérez-Lacorzana, J.M., Thierry, A. \& Weber, C., An integrated methodology to assess the benefits of urban green space. Science of the Total Environment, 334-335, pp. 489497, 2004.

[10] Hayward, D.G. \& Weitzer, W.H., The public's image of urban parks: past amenity, present ambivalence, uncertain future. Urban Ecology, 8, pp. 243 268, 1984.

[11] Godbey, G., Outdoor recreation, health, and wellness: Understanding and enhancing the relationship. Resources for the Future, 2009.

[12] Kemperman, A.D.A.M. \& Timmermans, H.J.P., Children's recreational physical activity. Leisure Sciences: An Interdisciplinary Journal, 33(3), pp. 183-204, 2011.

[13] Rabare, R.S., Okech, R. \& Onyango G. M., The role of urban parks and socio-economic development: case study of Kisumu Kenya. Theoretical and empirical researches in urban management, 3(12), pp. 22-36, 2009.

[14] CABE SPACE, Start with the park: Creating sustainable urban green spaces in areas of housing growth and renewal. Commission for Architecture \& the Built Environment, 2005.

[15] Morgan, P., Towards a developmental theory of place attachment. Journal of Environmental Psychology, 30, pp. 11-22, 2010.

[16] Livingston, M., Bailey, N \& Kearns, A., People's attachment to place - the influence of neighbourhood deprivation. Joseph Rowntree Foundation, 2008. 
[17] Budruk, M., Thomas, H. \& Tyrrell, T., Urban green spaces: A Study of place attachment and environmental attitudes in India, Society \& Natural Resources: An International Journal, 22(9), pp. 824-839, 2009.

[18] Ramkissoon, H., Weiler, B. \& Smith, L.D.G., Place attachment and proenvironmental behaviour in national parks: The development of a conceptual framework. Journal of Sustainable Tourism, 20(2), pp. 257-276, 2012.

[19] Loures, L. \& Costa, L., The role of urban parks to enhance metropolitan sustainability: The case of Oporto. International Journal of energy and environment, 4(6), pp. 453-461, 2012.

[20] Erkip, F., The distribution of urban public services: The case of parks and recreational services in Ankara. Cities, 14(6), pp. 353-361, 1997.

[21] Louv, R., Last child in the woods: saving our children from nature-deficit disorder, Algonquin Books of Chapel Hill: New York, 2008. 